\title{
Synthesis, characterisation and cytotoxicity of gold microwires for ultra-sensitive biosensor development
}

\author{
Nurul Akmal Che Lah ${ }^{1}$, Robert Gray ${ }^{2}$ and Sonia Trigueros ${ }^{3^{*}}$ (])
}

\begin{abstract}
With the long-term goal of developing an ultra-sensitive microcantilever-based biosensor for versatile biomarker detection, new controlled bioreceptor-analytes systems are being explored to overcome the disadvantages of conventional ones. Gold (Au) microwires have been used as a probe to overcome the tolerance problem that occurs in response to changes in environmental conditions. However, the cytotoxicity of Au microwires is still unclear. Here, we examined the cytotoxicity of Au microwires systems using both commercial and as-synthesised Au microwires. In vitro experiments show that commercial Au microwires with an average quoted length of $5.6 \mu \mathrm{m}$ are highly toxic against Gram-negative Escherichia coli (E. coli) at $50 \mu \mathrm{g} / \mathrm{mL}$. However, this toxicity is due to the presence of CTAB surfactant not by the microwires. Conversely, the as-synthesised Au microwires show non-cytotoxicity even at the maximum viable concentration $(330 \mu \mathrm{g} / \mathrm{mL})$. These findings may lead to the development of potentially life-saving cytotoxicity-free biosensors for an early diagnostic of potential diseases.
\end{abstract}

Keywords: Biosensor, Biomarkers, Antimicrobial, Cytotoxicity, Gold microwires

\section{Introduction}

A wide array of biomarkers secreted by cancerous cells can be found in blood samples [1-6]. With current emerging proteomics technologies, it is straightforward to obtain reliable sets of disease-specific protein biomarkers. Early identification of disease blood protein signatures, is becoming the most promising strategy for effective cancer prevention [7-10]. Nevertheless, some protein biomarkers, such as those secreted by cell death in tumours microenvironment at a very early growth period, are produced only at ultra-low concentrations [11-14]. Low reproducibility highlights the difficulty in detecting low concentrations of disease protein biomarkers. With concentration, the scales are six to seven orders of magnitude lower than the plasma protein (e.g. the

\footnotetext{
*Correspondence: sonia.trigueros@zoo.ox.ac.uk

${ }^{3}$ Department of Zoology, University of Oxford, Oxford OX1 3PS, UK

Full list of author information is available at the end of the article
}

reference range of albumin protein in blood is approximately $35-55 \mu \mathrm{g} / \mathrm{L}[15,16])$, making their detection challenging. Engineered materials-based biosensors with high sensitivity levels have been the focus of improved biomarker detection technology [17-20]. These advanced detection methods depend on the antibody and protein for recognition, identification and quantification of targeted cells.

There are several drawbacks on microcantilever (MC) biosensor, $\mathrm{MC}$ requires a high amount of analytes and should be sensitive enough to measure deflection in the range of few micrometres leads $[21,22]$ to the integration of microfluid biosensor layer for protein-protein interaction detection [23]. Hence, micromaterial-based MC biosensors have good potential in advanced biosensor technology as they offer a excellent surface-to-volume ratio, so they are able to mediate faster with a higher kinetic electron transfer, allowing the merit of multiple sensing mechanisms in a single platform $[18,24-26]$. The 
size of micromaterials can facilitate effective interaction depending on the nature of the chemical bonding with targeted biomolecules in opaque liquids such as blood or urine $[27,28]$. Offering potential for electronic detection surface stress functionalisation as a result of the MC bending by a certain extent generated by analyte-ligand interactions in the biomarker layer.

Gold $(\mathrm{Au})$ based one-dimensional (1-D) micromaterial is a candidate for achieving an ultrasensitive $\mathrm{MC}$ biosensor device [28-33]. Specifically, for flexible chemo resistive sensors. $\mathrm{Au}$ microwires are attractive because they possess minimal cross-sectional area but have the ability to increase the flood-current along the axial current direction, resulting in higher conductance changes compared to the typical zero-dimensional (0-D) micromaterials [34]. The chemoreceptive characteristics of AuNWs such as the capability to serve as biocompatible surface for the immobilisation of biomolecules in a correct orientation which enhances the binding affinity of antigen-antibody and the ability to support a swift electron-transfer which causes the flow of one-way electron between two electrodes are key considerations in designing the MC microbiosensor $[19,20]$. Chemoreceptive and also conductometric characteristics played by the $\mathrm{Au}$ microwires are both important for biosensor transduction mechanism.

On the other hand, there have been many concerns about the potential cytotoxicity of micromaterials in general, which may arise upon medical application [35-37]. It has been proved that several micromaterials consisting of heavy metals may release ions that may cause cytotoxic effects. Although Au microwires are not considered toxic in most cases, there is a certain ambiguity about $\mathrm{Au}$ microwires toxicity impact regarding variability and threshold for specific cell types [38]. Therefore, there is an urgent need to present new data that can assist in developing a mass-sensitive MC-based Au microwires biosensor. Important primary parameters that are involved in cytotoxicity assessments of $\mathrm{Au}$ microwires include the aspect ratio of microwires, surface functionalisation method, cell type, administration of dosage and application protocols. In this work, we describe the synthesis of bio-friendly Au microwires for MC biosensor application (see Additional file 1: Figure S1). The objective is to ascertain the maximum dose of as-synthesised Au microwires which is safe to avoid initial cytotoxicity whilst increasing the sensitivity of the microwires array in comparison with commercial $\mathrm{Au}$ microwires suspended in CTAB. Bacteria cells are the most sensitive cells to detect toxicity arising from either free or microstructured metallic ions. For toxicity detection, we use a set of antimicrobial approaches. The transduction mechanism of microsensors depends on the binding of the protein of interest change which yields different conductivity output. The Au microwires play a vital role in the transduction mechanism. Hence it is essential to maximise the concentration of $\mathrm{Au}$ microwires to achieve maximum sensitivity. The investigation of the transduction mechanism is not within the scope of this study. The assembling microwires on the top surface of the microscopy probe is also evaluated but not discuss further in the present study and only included in Additional file 1. Any biomarker should be able to be detected using this platform.

\section{Materials and methods}

\section{Au microwires preparation}

Oleylamine, OA (technical grade 70\%), triisopropylsilane, TIPS (98\%), hexane $\left(\mathrm{CH}_{3}\left(\mathrm{CH}_{2}\right)_{4} \mathrm{CH}_{3}\right.$, anhydrous, 95\%) and ethanol $\left(\mathrm{CH}_{3} \mathrm{CH}_{2} \mathrm{OH}\right.$, absolute, $\left.\geq 99.8 \%\right)$ were purchased from Merck Sigma-Aldrich, United Kingdom. All the chemicals were used without further purification.

Commercial AuNWs (dispersion in $\mathrm{H}_{2} \mathrm{O}$, contains cetyl trimethyl ammonium bromide, $\mathrm{CTAB}$ as a stabiliser) used was purchased from Merck Sigma-Aldrich, United Kingdom. The AuNWs is specified to have an average diameter size and length of $30 \mathrm{~nm}$ and $4.5 \mu \mathrm{m}$, respectively, with a concentration of $\geq 50 \mu \mathrm{g} / \mathrm{mL}$. Nonetheless, the size and length observed under the FESEM are in micrometer size range.

\section{Microbial cell culture preparation}

The commercial Escherichia coli (E. coli) DH5-Alpha strain $(D H 5 \alpha)$, an engineered non-pathogenic strain for routine subcloning procedures is used in the present work. It is quick and easy to grow and has been used extensively as a lab microbial model system. (ThermoFisher catalogue number 18263618). E. coli cells were grown in Luria-Bertani medium (LB), rich medium for cell growth. The cells were initially grown from an original culture sample, kept at $-80{ }^{\circ} \mathrm{C}$. Cells were inoculated onto an LB agar plate and incubated at $37{ }^{\circ} \mathrm{C}$ for $24 \mathrm{~h}$. At this point, a number of individual colonies had grown, each from a single cell. To reduce variation across the bacteria under study, a single colony was selected and incubated in LB to produce a working cell solution. This was used as the master cell culture for all the bacteria cell experiments. Optical cell density measurements were acquired using a Perkin Elmer Lambda Bio ${ }^{+}$ Spectrophotometer (Germany). The spectrophotometric method measured the optical density at $600 \mathrm{~nm}$ based on an American Public Health Association (APHA) standard. The optical density (OD) of 0 is set for pure LB, and the spectrophotometer is calibrated so that the OD equal to 1.00 corresponds to a cell density of $109 \pm 5 \times 108$ / $\mathrm{mL}$. A linear relationship between OD and cell density is achieved over this range. 


\section{Cytotoxicity validation methods Disk diffusion assay}

Cytotoxicity test is carried out through the agar disk diffusion assay method which has been used in many clinical microbiology laboratories for routine antimicrobial susceptibility testing. The standard measurement is based on the Clinical Laboratory Standard Institute (CLSI) and manufacturers' standard for each sample. The $\mathrm{Au}$ microwires colloidal solution $(300 \mu \mathrm{g} / \mathrm{mL})$ was suspended in distilled water and this portion deposited on the sterile paper disk that is $6 \mathrm{~mm}$ in diameter with 4 replicate disk per sample. The disk was placed on Gram-negative $E$. coli $D H 5 \alpha$ strain. Controls were prepared using pure hexane and/or distilled water.

Escherichia coli DH5 $\alpha$ were inoculated at a concentration of 107 to 108 cells/mL at stationary phase strain onto Luria-Bertani (LB) agar. The LB agar plates were then inoculated and incubated for $24 \mathrm{~h}$ at $37^{\circ} \mathrm{C}$ to record the cytotoxicity effect. The size of the inhibition zone around the disc is control by the interchange between the $\mathrm{Au}$ microwires diffusion rate (Eq. 1), the exponential growth rate of the bacteria and the minimum inhibitory concentration which is usually higher than the breakpoint.

$$
C(r, t)=\frac{A \cdot e^{\left(\frac{-r^{2}}{4 D t}\right)}}{4 \pi h D t} .
$$

The $C$ is referring to the $\mathrm{Au}$ microwires concentration at time $(t)$ and distance $(r)$ from the point source (disc centre) with the diffusively isotropic assumption in a 2-D plate form. The $D$ is the corresponding diffusion coefficient and $A$ is the amount of initial Au microwires used in the disc with $h$ is the height of the agar in the plate. The concentration of $\mathrm{Au}$ microwires in the inhibition zone could drop below the minimum inhibitory concentration after overnight incubation. By this time, the diffusion of the nutrient in the plate occurs and gradually depleted by the bacteria that grew in the inhibition zone periphery. Overnight incubation made the cells cover almost 70\% of the growing surface, except for the circles of growth surrounding disc which remained clear. The diameters of these circles are then measured and used as measurements of the inhibitory effects of the sample.

\section{Colony forming unit counting method (CFU)}

Methods for in vitro evaluation of antimicrobial activity, seek to assess the total number of $E$. coli cells in culture media [39]. Colony-forming units (CFU) of E. coli DH5 $\alpha$ were counted after plating triplicate serial dilutions of LB cultures on LB-Agar plates and incubating overnight at $37{ }^{\circ} \mathrm{C}$. Plates containing between 2 and 200 individually identifiable colonies were counted. The relative number of colonies on a plate compared to the control gives a value which is a measurement of the toxicity.

\section{Microstructures characterisation methods Characterisation of as-synthesised and commercial Au microwires}

$\mathrm{Au}$ microwires were resuspended and sonicated in ethanol medium. And let it dry on an aluminium substrate at room temperature. Field emission scanning electron microscopy (FESEM) imaging was conducted by a JEOL JSM $7500 \mathrm{~F}$ microscope equipped with a cold field emission gun at an acceleration voltage of $15 \mathrm{kV}$. An in-lens detector collected secondary electrons and backscattered electrons signals and in-chamber multi-quadrant annular retractable solid-state detector, respectively. Element analysis was carried out using Zeiss Neon 40EsB (Carl Zeiss NTS GmbH, Oberkochen, Germany) at $20 \mathrm{kV}$ equipped with energy dispersive $\mathrm{x}$-ray spectroscopy, EDX (Inca software, Oxford Instruments). Image analysis on FESEM data was carried out using ImageJ $1.50 \mathrm{i}$. $\mathrm{Au}$ microwires density was determined using the plugin 'analyse particles' function of ImageJ on a total of 20 SEM images of $\mathrm{Au}$ microwires samples. The aggregated size of $\mathrm{Au}$ microwires was calculated from a total of 2000 randomly picked aggregated Au microwires from FESEM images.

\section{Results}

\section{Synthesis of Au microwires}

$\mathrm{Au}$ microwires were synthesised based on the method described in the literature [34]. In the absence of heat, the synthesis reaction involved mixing of $100 \mu \mathrm{L} \mathrm{OA}$ and $150 \mu \mathrm{L}$ TIPS with about 3 to $5 \mathrm{mg}$ of gold (III) chloride precursor solution, $\left(\mathrm{HAuCl}_{4} 99.9 \%\right.$ trace metals basis, $30 \mathrm{wt} \%$ in dilute $\mathrm{HCl}$ ) in $2.5 \mathrm{~mL}$ final volume of hexane without stirring. OA acts as a stabiliser and a template for 1-D growth with TIPS role as a highly reactive reducing agent. The observation of the reaction through the change in colour from light orange to red, followed by dark violet during the period of reaction left out at room temperature is demonstrated in Fig. 1. The Au microwires products were centrifuged, washed with ethanol at least 3 times and finally re-dispersed in hexane for further characterisations. In this work, the resulting $\mathrm{Au}$ microwires were more than $100 \mathrm{~nm}$ in diameter with a standard deviation of $0.8 \%$. During the synthesis reaction, the potential of $\mathrm{Au}^{+}$reduction to $\mathrm{Au}$ is higher in the presence of OA $[40,41]$. The primary limiting factor for constant electron transfer rate would be the OA reagent. The relative concentration of the Au microwires obtained was $>50 \mu \mathrm{g} / \mathrm{mL}$. This method can also be applicable for the synthesis of other metal microwires as long as the chemical combination is suitable and correct. 


\section{$\mathrm{Au}(\mathrm{III})$ ions + OA + TIPS}
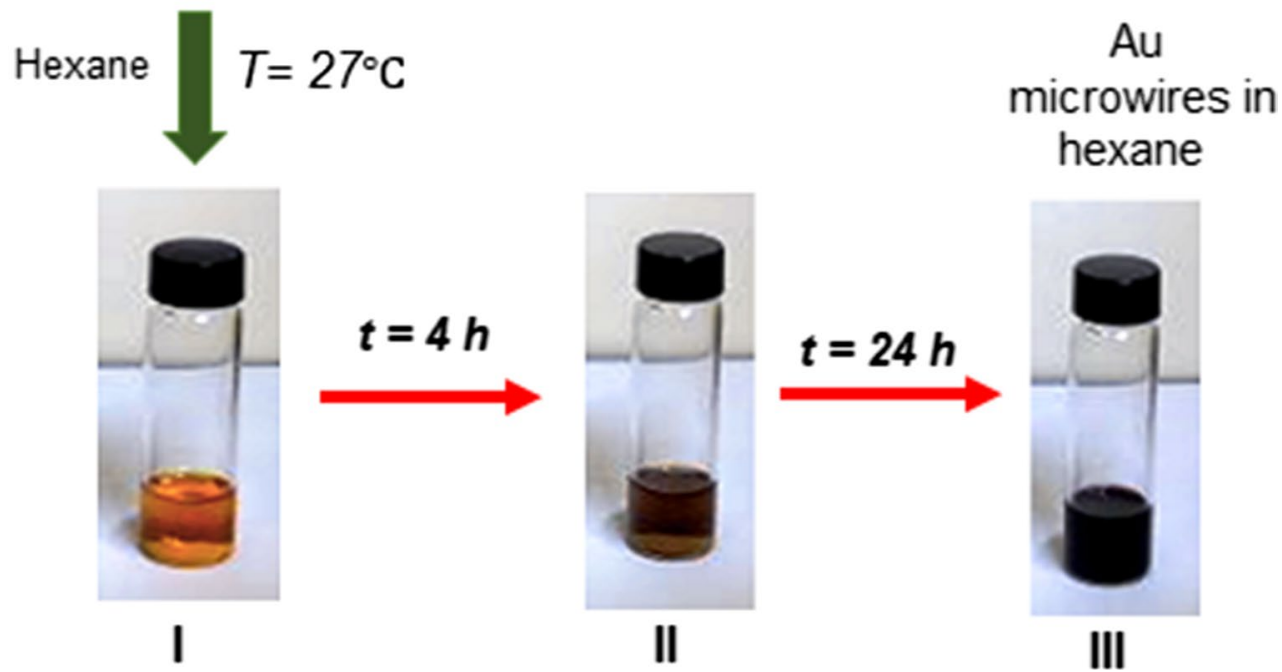

Fig. 1 As-synthesised Au microwires reaction formation flow. I The solution of $\mathrm{HAuCl}_{4} \cdot 3 \mathrm{H}_{2} \mathrm{O}+\mathrm{OA}+\mathrm{TIPS}$ after 1 min of the mixture. II After the mixture is left at room temperature for $4 \mathrm{~h}$ and III $24 \mathrm{~h}$. The reaction product has a dark violet colour solution after $24 \mathrm{~h}$

\section{Morphological properties of as-synthesised and commercial Au microwires}

The as-synthesised Au microwires samples obtained were characterised for their morphological properties by standard techniques. The morphology, distribution and purity of the as-synthesised Au microwires verified by FESEM are shown in Fig. 2a. For a $24 \mathrm{~h}$ reaction, the resultant colloid colour is dark violet which indicates extended filament-like structures. The $\mathrm{Au}$ microwires tend to self-assemble into 1-D networks and forming closely packed parallel structures. The use of negatively charged TIPS in the synthetic reaction at room temperature controls the acceleration of the process [42, 43]. The size distribution of parallel $\mathrm{Au}$ microwires bundles was difficult to measure. Higher magnification of the assembled ultra-thin Au microwires was unachievable due to their highly sensitive towards the electron beam which resulted in melted microwires within a few seconds of exposure. However, it is expected that the $\mathrm{Au}$ microwires possess diameters of approximately larger than $100 \mathrm{~nm}$ with an aspect ratio (length-to-width ratio) above $1000 \mathrm{~nm}$. In this case, the Au microwires tended to form a stack of parallel bundles (yellow rectangular) which then self-assembled into 1-D network structures over macroscopic distances through a spontaneous directional aggregation that occurs during solvent evaporation. The directional aggregation is typically formed via oriented attachment in which Au microwires are permitted to fuse as the chemical potential between each chain is different. Therefore, the smoothing extension process to interconnect the of the microwires takes place through diffusion. The $\mathrm{Au}$ microwires exhibit higher stability in a polar solvent which is favourable for the subsequent immobilisation of biomolecules.

The primary objective of this work is to produce $\mathrm{Au}$ microwires with high aspect ratio and analyse the elements of samples with the quantitative and qualitative analyses properties. Figure $2 \mathrm{~b}$ shows the element composition of obtained Au microwires samples using EDX. The EDX point measurements were carried out for an accurate estimation of $\mathrm{Au}$ amount present in each sample. For as-synthesised $\mathrm{Au}$ microwires, the amount of $\mathrm{Au}$ is at the level of $98 \%$ as the major element in the sample with the remaining amount is $\mathrm{Si}$ (substrate). The presence of high purity $\mathrm{Au}$ has resulted from homogeneous nucleation of metallic $\mathrm{Au}$ as spherical clusters and hence determined the growth of 1-D microwires. This condition proves that in the presence of TIPS, Au seeds have rapid kinetics in the formation of microwires.

On the other hand, the representative FESEM images of commercial $\mathrm{Au}$ microwires suspended in $\mathrm{CTAB}$ aqueous solution are shown in Fig. 3. It has been observed that the network formed does not assemble into ordered microstructures (Fig. 3a) as seen in the as-synthesised $\mathrm{Au}$ microwires sample beforehand. Instead, the commercial Au microwires are randomly self-gating forming junction connection. Some of the Au microwires showed thicker diameter with reduced lengths as demonstrated in Fig. 3b, c. The Au microwires can be as long as $171 \mu \mathrm{m}$ (Fig. 3d). 
a
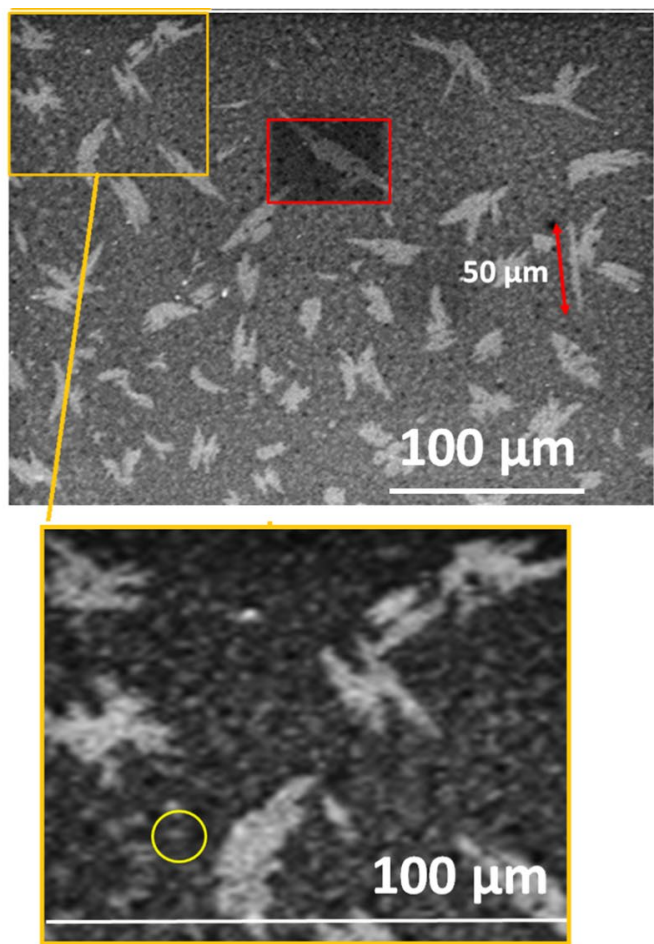

b

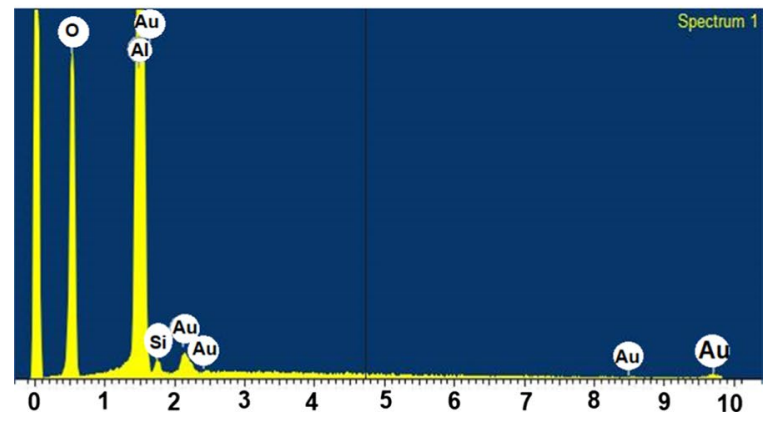

Fig. 2 a The representative FESEM micrograph of the as-synthesised AuNWs. The enlarged figure (yellow rectangular) reveals the parallel self-assembly arrangement of close-packed AuNWs bundles. The small parallel bundle highlighted in yellow circle showed that the bundle of the microwires has a diameter size of $\sim 200 \mathrm{~nm}$. b The EDX spectrum analysis of the as-synthesised AuNWs recorded for the selected area of AuNWs (red rectangle) taken from image a

One can see that the diameters of the microwires were averagely thin and approximately $d_{a v} \sim 540 \mathrm{~nm}$ as indicated in Fig. 3e. Interestingly, the $d_{a v}$ specified by the supplier is $\sim 30 \mathrm{~nm}$. It is common to have different values of diameter and length from the specified information properties provided by the supplier as they are in a discrete condition and slight changes in the physical handling, as well as the time storage, would affect the properties of the sample. Apparently, Au, in its nature, is quite malleable [44-47]. Thus, it facilitates the aggregation, which also correlates to the changes of their stability property. CTAB is used to minimise the aggregation, but it would not be able to halt the entire aggregation of the $\mathrm{Au}$ microwires. In this case, CTAB is considered as an effective stabiliser which proved by the average diameter, $d_{a v}$ distribution provided in the histogram (Fig. 3e). The $d_{a v}$ distribution is dominantly conquered by the $540 \mathrm{~nm}$ based on the highest per cent frequency distribution $(68 \%)$, while the larger $d_{a v}$ microwires $\left(d_{a v} \sim 1.25\right.$ to $7.14 \mu \mathrm{m})$ with the per cent frequency is only $3 \%$ measured by the Gaussian distribution. This indicates that the $540 \mathrm{~nm}$ of $d_{a v}$ majorly contributes to the overall properties of the sample.

The average length of microwires, $L_{a v}$ typically remained the same caused by the similar diffusion of intense high energy ions in the surrounding. The $L_{a v}$ polydispersity distribution of the commercial $\mathrm{Au}$ microwires is shown in Fig. 3f. The narrow length distribution range (up to $\sim 30 \mu \mathrm{m}$ ) indicates that the commercial $\mathrm{Au}$ microwires were stable and monodispersed. The wide distribution range is due to the more considerable length variation, which is up to $\sim 171 \mu \mathrm{m}$.

It shall be noted that the cloudy region encircling $\mathrm{Au}$ microwires is due to the strongly coupled capping action of CTAB upon the evaporation of the solvent, leaving the residue behind. Since cationic CTAB surfactant consists of long carbon atomic chain [48-50], it functions as space-filling of secondary material that fills up the gaps between the Au microwires and maintains the individual distribution of Au microwires. The FESEM micrographs distinctly manifest dissimilarity of CTAB grain with $\mathrm{Au}$ microwires, exhibiting large-sized flake grains (marked with the blue arrow in Fig. 3). As stated in few reports [51-53], the tertiary ammonium ion cationic headgroup in the presence of bromide anion as a counterpart in microwire solution results in higher binding affinity and leads to more stable bilayer on the microwire surface. The addition of CTAB micelle helps to stabilise Au microwires when the equilibrium condition is achieved through the occupation some of the surface areas caused by the increased in the aggregation number of CTAB micelle. This stabilisation effect, while making them soluble, can be an inhibitor of subsequent self-assembling process.

\section{Cytotoxicity evaluation of as-synthesised and commercial Au microwires}

The proof-of-concept on the cytotoxicity of the sensorsbased microwires requires long acquisition times. Some of the microwires conventional synthesis protocols, such as the reduction of $\mathrm{Au}$ precursor in the presence of capping agent can introduce toxic materials from surface conditioning and chemistry $[36,54,55]$. These including 
a

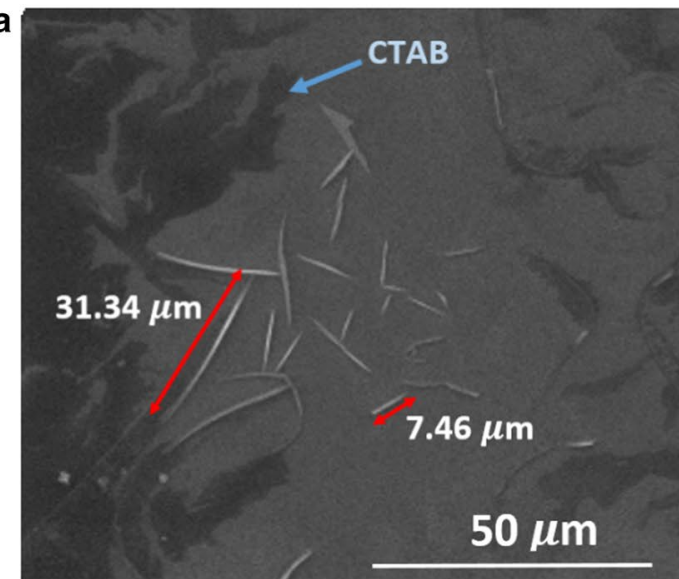

C
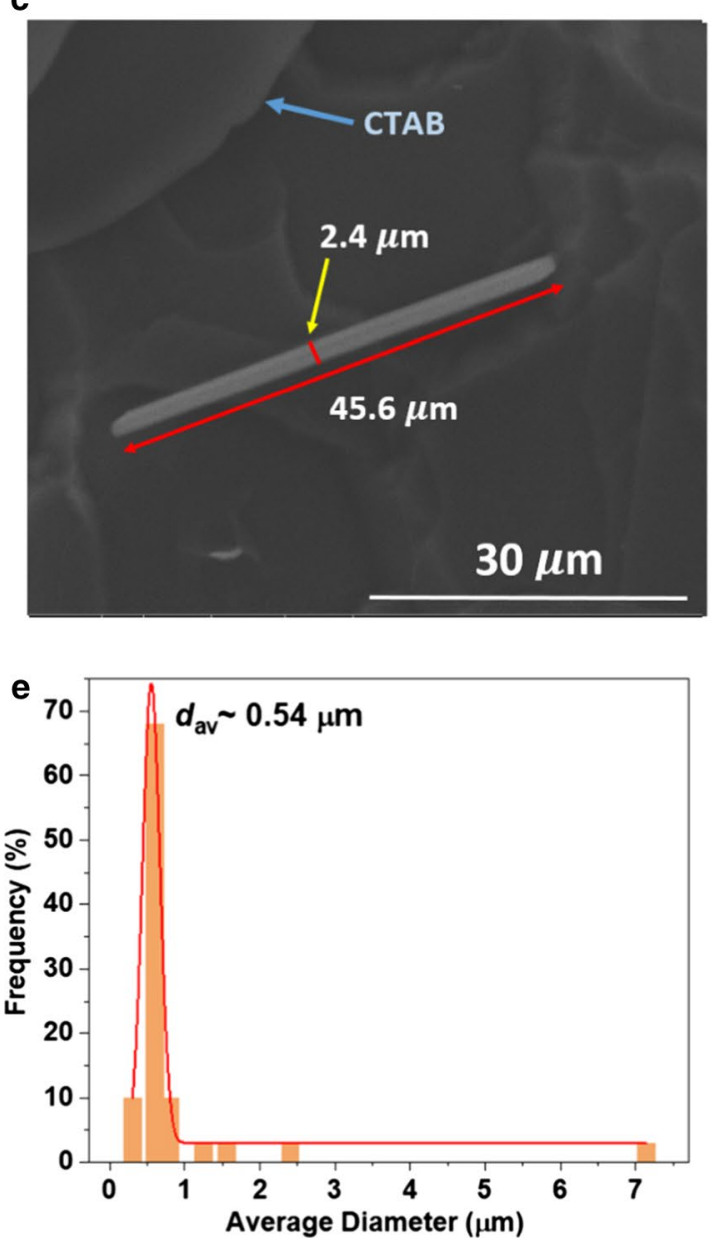

b

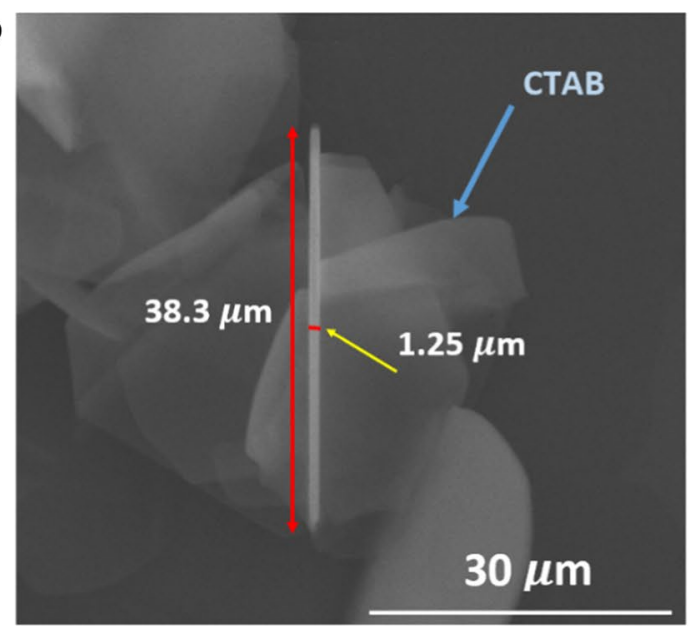

d
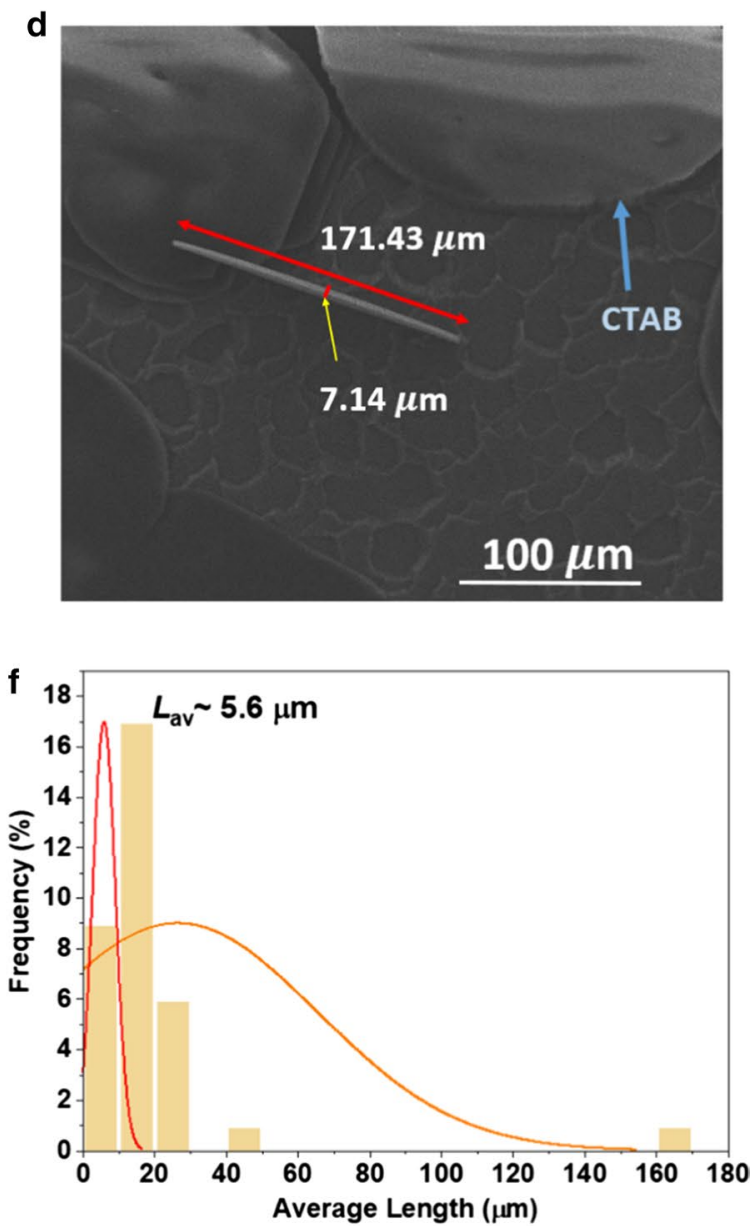

Fig. 3 a Representative of FESEM images of sonicated commercial Au microwires with CTAB as a capping agent. b-d Indicate the individual Au microwires. $\mathbf{e}$ The corresponding diameter and $\mathbf{f}$ length distributions of the commercial Au microwires in an aqueous solution of CTAB. The average diameter and length of the Au microwires are 0.54 and $5.6 \mu \mathrm{m}$, respectively, indicated by the Gaussian plot (red line)

surface charge and capping stabilisation without 'green' physical approach profited from natural microstructure generation. Additionally, the metal itself can produce toxicity and thus, being unfavourable for in-vivo applications. Taking into consideration the unique advantages of Au microwires, different capping interface, these types of 
Au microwires exhibits a significant effect in microbial viability. For this reason, we examined the potential cytotoxicity propensity for commercial and as-synthesised of Au microwires.

To further demonstrated the cytotoxicity tolerance in as-synthesised and commercial $\mathrm{Au}$ microwires samples, the commercial bacteria E. coli $D H 5 \alpha$, an engineered non-pathogenic bacterial strain is extensively used as a lab cytotoxicity microbial model system. Two types of cytotoxicity test were carried out. The first is the disc diffusion assay. This method is performed to detect cytotoxicity by inducing a gradient of concentration (Fig. 4a)

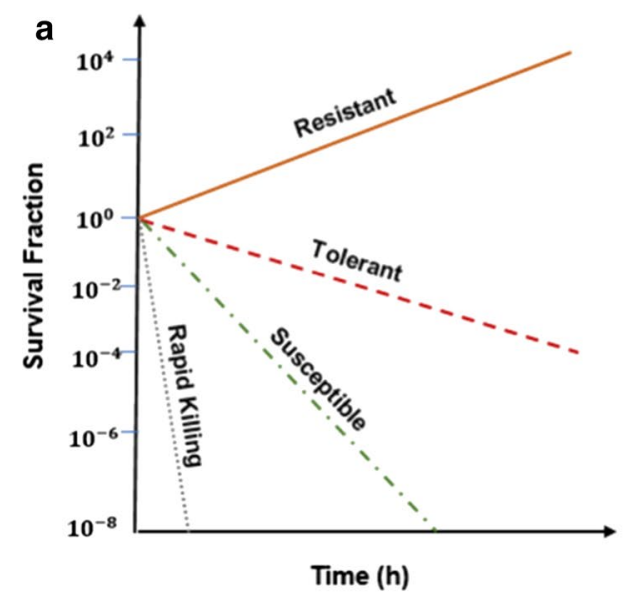

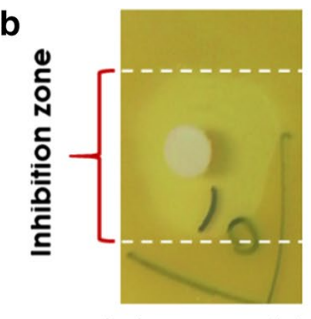

$50 \mu \mathrm{g} / \mathrm{ml}$ commercial AuNWs (tolerant)

d

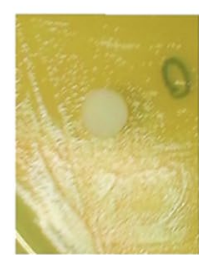

Water

(resistant)
C

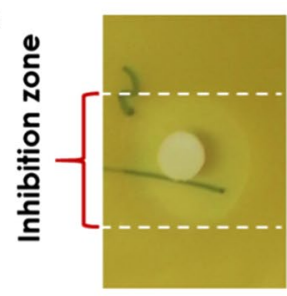

$10 \mu \mathrm{g} / \mathrm{ml}$ commercial AuNWs (susceptible)

e

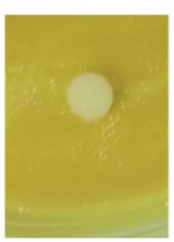

Hexane (resistant)

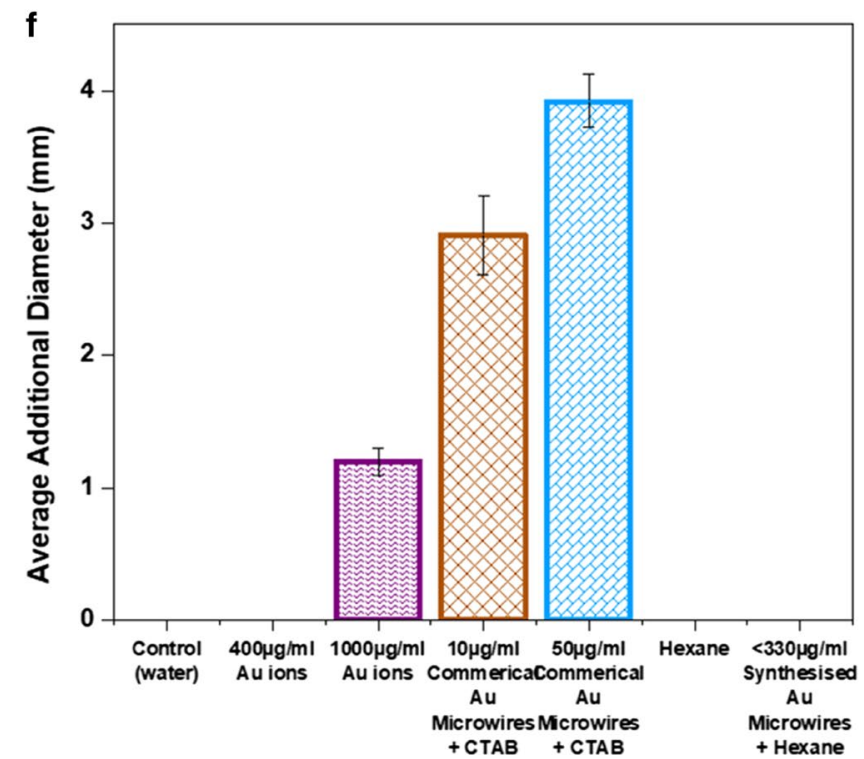

Fig. 4 The representative image of E. coli DH5a responses to the Au microwires solutions. The disc diffusion assay results with E. coli DH5a cells $(100 \mu \mathrm{L})$ on LB agar overlay. $\mathbf{a}, \mathbf{b}$ Indicate the white dotted lines mark the diameter of the white zone where the growth of E. coli DH5a is prevented by the Au microwires (inhibition area). $\mathbf{a}$ Is a tolerant strain with $\mathbf{b}$ is the susceptible strain. A slightly larger zone of inhibition is seen for tolerant strain due to growth delayed. $\mathbf{c}$, $\mathbf{d}$ Are referring to control sample of water and hexane solutions, respectively. Both show resistant strain. $\mathbf{e}$ Schematic illustration on the differences between the fraction of surviving bacteria for resistant, tolerant, susceptible and rapid killing strains. $\mathbf{f}$ Disc diffusion measurements obtained using several concentrations of Au ions and both the as-synthesised and commercial Au microwires. The bars represent one standard error 
around a disc (known as inhibitory effect) loaded with $\mathrm{Au}$ microwires. The inhibitory effect among the E. coli DH5 $\alpha$ strains exhibited different outcomes. The ratio of the ring area (measure in $\mathrm{mm}$ ) is directly proportional to the sample toxicity (white lines) as indicated in Fig. 4 b, c. The results show that the gradient of commercial Au microwires suspended in CTAB halts the growth of bacteria and creates an inhibition zone around the disc in both the 10 and $50 \mu \mathrm{g} / \mathrm{mL}$ samples. Lower inhibition zone was found for $1000 \mu \mathrm{g} / \mathrm{mL} \mathrm{Au}$ ions. For these types of $\mathrm{Au}-$ based suspensions, the largest inhibition zone reached $3.9 \pm 0.2 \mathrm{~mm}, 2.9 \pm 0.3 \mathrm{~mm}$ and $1.2 \pm 0.1 \mathrm{~mm}$ for $50 \mu \mathrm{g} /$ $\mathrm{mL}$ commercial AuNWs-CTAB, $10 \mu \mathrm{g} / \mathrm{mL}$ commercial $\mathrm{Au}$ microwires-CTAB and $1000 \mu \mathrm{g} / \mathrm{mL} \mathrm{Au}$ ions, respectively. Non-toxic samples with no inhibitory effect which refer to water (Fig. 4d) and hexane (Fig. 4e) samples. A similar observation was found for $400 \mu \mathrm{g} / \mathrm{mL}$ Au ions and $<330 \mu \mathrm{g} / \mathrm{mL}$ as-synthesised $\mathrm{Au}$ microwires suspended in hexane. The six samples used to observe the average diameter of inhibition zones containing Au-based solutions is presented in Fig. 4f.

The size of as-synthesised $\mathrm{Au}$ microwires prepared with growth solution contained $\mathrm{Au}$ microwires with a smaller length. Since hexane is a non-polar solvent, it has no charge. Thus, the conjugated surface of Au microwires with negatively charge of the hydrophobic OA, yield a negative surface charge of the $\mathrm{Au}$ microwires system $[34,56]$. As a result, no electrostatic interactions due to absent of different charges in the solution between the cell surface and as-synthesised Au microwires suspended in hexane. As generally accepted, CTAB alone is highly toxic cationic surfactant [57-59] and the conjugate systems of Au microwires-CTAB are proven to still contribute to toxicity to culture cells especially when the elevated concentrations of CTAB are present $(50 \mu \mathrm{g} / \mathrm{mL}$ commercial $\mathrm{Au}$ microwires-CTAB). With increasing the amount of Au microwires-CTAB solution, the cytotoxicity of the sample is increased caused by the nonspecific binding tendency of CTAB to negatively charged cell surfaces by electrostatic interactions [57, 60]. Once the interaction with the cell occurs, it forms blebs and holes on the cell and leading to cell death evident by the increase in the diameter of the ring zone. Moreover, the data also suggest that the abilities to induced cell death are also significant regardless of the aspect ratio of the Au microwires, in this case, the aspect ratio is constant for both 10 and $50 \mu \mathrm{g} / \mathrm{mL}$ commercial $\mathrm{Au}$ microwires-CTAB solution. To minimise the cytotoxicity effects in $\mathrm{Au}$ microwires$\mathrm{CTAB}$, the interaction between the membrane cell and CTAB should be blocked by using protein types of coating on the bilayer surface of CTAB. Meanwhile, a similar trend of nonspecific binding also observed when $\mathrm{Au}$ ions are incubated with the cell. The nonspecific binding was evident by the increased of the ring zone when exposed to the concentration of the $1000 \mu \mathrm{g} / \mathrm{mL} \mathrm{Au}$ ions. This nonspecific binding did not take place with $400 \mu \mathrm{g} / \mathrm{mL}$ $\mathrm{Au}$ ions might be due to the reduced content of positively charge $\mathrm{Au}$ ions, which in turn, decreases electrostatic interaction between the Au ions and negatively charged cell membrane. These results affirm cytotoxicity potency of commercial Au microwires-CTAB and Au ions compared to as-synthesised $\mathrm{Au}$ microwires suspended in hexane.

For further validation of cytotoxicity detection on commercial and as-synthesised Au microwires, the CFU enumeration is carried out after $24 \mathrm{~h}$ incubation (Fig. 5a). As evident from Fig. 5b, the CFU enumeration for $10 \mu \mathrm{g} /$ $\mathrm{mL} \mathrm{Au}$ ion measured viability of $72 \%$. At $30 \mu \mathrm{g} / \mathrm{mL} \mathrm{Au}$ ion approximates value were almost similar to the other one giving rise to $69 \%$. Cell-viability assessed by CFU remained at $100 \%$ on the control (water) sample. Compared with 10 and $30 \mu \mathrm{g} / \mathrm{mL}$ of $\mathrm{Au}$ ions, the cell incubated with a higher concentration of Au ions $(100 \mu \mathrm{g} / \mathrm{mL})$ was observed to be $0 \%$ cell viability. In the case of $2 \mu \mathrm{g} /$ $\mathrm{mL}$ of commercial Au microwires suspended in CTAB, $<300 \mu \mathrm{g} / \mathrm{mL}$ as-synthesised Au microwires and hexane also, $0 \%$ were viable for all in CFU enumeration. Pure hexane, water and the ionic $\mathrm{Au}$ at three different concentrations $(10,30$ and $100 \mu \mathrm{g} / \mathrm{mL}$ ) were used as negative controls. Assessment at $96 \mathrm{~h}$ was likely to be optimal for $\mathrm{Au}$ microwires strain. Indeed, the effect of both commercial and as-synthesised Au microwires along with a high dosage of $100 \mu \mathrm{g} / \mathrm{mL}$ Au-based ion seemed strong antibacterial agent in this assay. Considering the high amount concentration use for as-synthesised Au microwires, it is suggested that the Au microwires work markedly better, meaning presents less bacteria toxicity than $\mathrm{Au}$ ions (tenfold lower in concentration) as happened to other metallic materials.

Endowing the high antibacterial potency or toxicity effect based on the viability results for both types of $\mathrm{Au}$ microwires at those particular concentrations, another study is carried out to compare the inhibiting capability of commercial Au microwires-CTAB with $\mathrm{Au}$ microwires-sodium bicarbonate $\left(\mathrm{NaHCO}_{3}\right)$ towards the cell growth. The focused study is purposely done on the commercial $\mathrm{Au}$ microwires-CTAB since a relatively low amount of sample concentration used proved to affect the cell viability significantly. To further clarify the inhibitory antibacterial activity induced by the CTAB layer, commercial Au microwires were purified from CTAB capping layer and re-dispersed in $2 \mathrm{mM} \mathrm{NaHCO}$. Cells grown in $\mathrm{LB}$ media with $\mathrm{Au}$ microwires-CTAB and $\mathrm{Au}$ microwires- $\mathrm{NaHCO}_{3}$ with an approximate volume of $250 \mu \mathrm{L}$ for both were observed. Water served as the standard control. The cell-microwire-LB solutions were approximately 
a
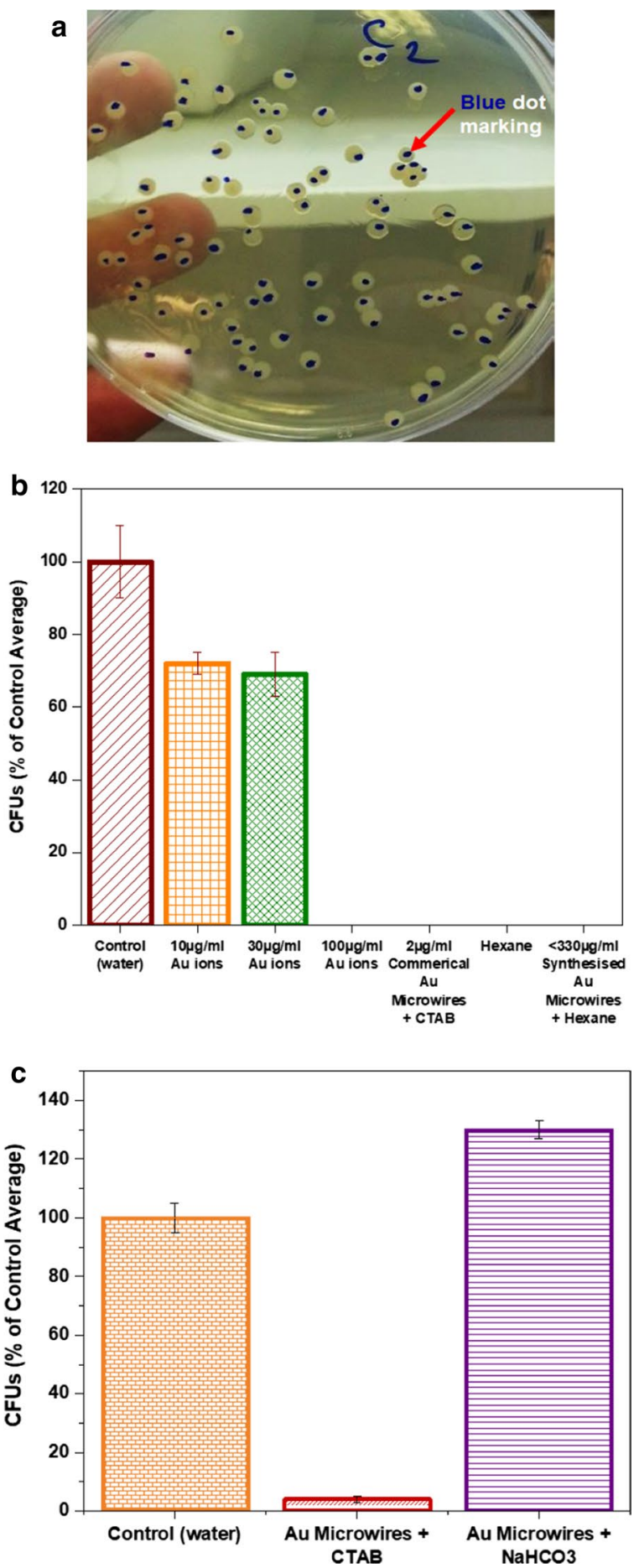

Fig. 5 a The representative of Au microwires antimicrobial CFU enumeration based on the individual colonies of $\mathrm{E}$. coli $\mathrm{DH} 5 \mathrm{a}$ formed after $24 \mathrm{~h}$. Blue marker was used to mark the colonies with dots marking at the bottom side of the petri dish. $\mathbf{b}$ The number of bacterial colonies (\%) appeared in agar plated treated with control (water), 10, $30 \mu \mathrm{g} / \mathrm{mL}$ and $100 \mu \mathrm{g} / \mathrm{mL}$ of Au ions, $2 \mu \mathrm{g} / \mathrm{mL}$ of commercial Au microwires suspended in CTAB, hexane and <330 $\mathrm{gg} /$ $\mathrm{mL}$ as-synthesised Au microwires in hexane. c Activity of antimicrobial CFU assay of Au microwires capped with CTAB and $\mathrm{NaHCO}_{3}$ after $24 \mathrm{~h}$ of plate-incubation. Water is used as a control sample
$5 \mu \mathrm{g} / \mathrm{mL}$, incubated for $90 \mathrm{~min}$ and was serially diluted to 105 times of the initial concentration with the set to dispense for $100 \mu \mathrm{L}$ onto plates. As shown in Fig. 5c, CFU enumeration showed $4 \%$ and $130 \%$ of capture efficiency for $\mathrm{Au}$ microwires-CTAB and $\mathrm{Au}$ microwires- $\mathrm{NaHCO}_{3}$ solutions, respectively. The low $\mathrm{CFU}$ in the $\mathrm{CTAB}$ solution was found to be threefold lower than in $\mathrm{NaHCO}_{3}$, indicating that the toxicological effect of CTAB is relatively high, which significantly displayed susceptible inhibit growth of E. coli cells. $\mathrm{NaHCO}_{3}$ had a low inhibitory effect.

The results demonstrated that surface modification is the decisive factor governing the cytotoxicity of $\mathrm{Au}$ microwires. CTAB proved the capability to induce E. coli $D H 5 \alpha$ cell death and destroy bacteria growth. As regards to the surface modification, the Au microwires capped with $\mathrm{NaHCO}_{3}$ (well-known as baking soda), indicated minimal toxicity effect and had almost no effect on cell viability in an alkaline environment. The alkaline environment retarded the activity of the toxicity which inhibits the cellular uptake. When combining with $\mathrm{NaHCO}_{3}$, the acidic environment that usually leads to cell death is halts and decreasing the risk of adverse effects and toxicity.

It is believed that the primary toxicity mechanism of the Au microwires-CTAB was via the activation of intracellular cell damage, which rigidly controls the per cent of cell survival. As the cell tries protecting itself from toxicity created by the molecule, other existing plasma proteins will adsorb on the surface of microwires. The microwires eventually penetrate the cells after adjusting the interfacial properties of the adsorbed protein shell. However, some of the adjustments are not always a success as not all modified Au microwires surface would able to enter the cells effectively. The proper conjugated $\mathrm{Au}$ microwires able to recognise the proteins on the cell membrane. Thus, adsorption of the protein to the surface of the microwires mediate the direct penetration of microwires. Typically, smaller Au microwires are frequently deemed as more toxic due to the ability to fully penetrate at intracellular locations (e.g., nucleus) which is not able to get through by larger microstructures. Hence, since cytotoxicity was controlled by the physicochemical surface properties (surface charge number and dimensions) of Au microwires, it is crucial to employ riskless surface modification reagent to govern the biological effects of microwires to ensure the safety of microstructures used in medical applications.

\section{Conclusions}

As discussed, the synthesis of Au microwires has tailored microwires that formed the irregular chain-like oriented assembly. These $\mathrm{Au}$ microwires in hexane solution are almost similar in average length and ten 
times smaller in diameter size as compared to commercial Au microwires suspended in CTAB solution. However, they are unstable at relatively high temperatures, melting within a few seconds upon the heat exposure. The anionic polymer of OA was used as a capping layer to protect as-synthesised $\mathrm{Au}$ microwires from aggregation, which also render them to be biocompatible. The feasibility of the Au microwires reveals that the functionalised $\mathrm{Au}$ microwires in the present of OA was able to avoid cytotoxicity to the membrane cell. On the other hand, the commercial $\mathrm{Au}$ microwires in high crystallinity state are stable at elevated temperatures and the toxicity responds observed is mainly caused by the CTAB capping layer and not due to the aspect ratio of the Au microwires. In fact, the pristine Au microwires alone was generally nontoxic and proved to have low cytotoxicity when capped with $\mathrm{NaHCO}_{3}$ upon eliminating the CTAB layer on the microwires. These different surface modifications have shown that the cytotoxicity of Au microwires is closely related to the original physicochemical properties of the capping layer based on the in vitro cell investigation results. Hence, the as-synthesised $\mathrm{Au}$ microwires and the $\mathrm{Au}$ microwires- $\mathrm{NaHCO}_{3}$ could be considered as the optimal options for integrating and implanting in MC biosensor devices, including high-throughput applications.

\section{Supplementary information}

Supplementary information accompanies this paper at https://doi. org/10.1186/s12934-020-01478-y.

Additional file 1. The assembling microwires on the top surface of the microscopy probe is also evaluated but not discuss further in the present study and only included in the Supplementary Materials section.

\section{Acknowledgements}

All individuals listed as authors have contributed substantially to the experimental and discussion of the reported work. ST and RG were supported by EPSRC IAA D4D00620. S.T. also acknowledges support from the Oxford Martin School and DNANO.Ltd. N.C.L was supported by University Malaysia Pahang RDU1703152 and RDU190360.

\section{Authors' contributions}

ST conceived and designed the experiments; ST, RG and NCL performed the experiments. ST, RG and NCL wrote the manuscript. All authors read and approved the final manuscript.

\section{Funding}

ST and RG were supported by EPSRC IAA D4D00620. S.T. also acknowledges support from the Oxford Martin School and DNANO.Itd UK. N.C.L was supported by University Malaysia Pahang RDU1703152 and RDU190360.

\section{Availability of data and materials}

Data are available on request due to privacy or other restrictions.

\section{Ethics approval and consent to participate}

Not applicable.

\section{Consent for publication}

Not applicable.

\section{Competing interests}

The authors declare that they have no known competing financial interests or personal relationships that could have appeared to influence the work reported in this paper.

\section{Author details \\ ${ }^{1}$ Innovative Manufacturing, Mechatronics and Sports Lab (iMAMS), Faculty of Manufacturing and Mechatronics Engineering Technology, University Malaysia Pahang, 26600 Pekan, Pahang, Malaysia. ${ }^{2}$ University College London, Gower St, Bloomsbury, London WC1E 6BT, UK. ${ }^{3}$ Department of Zoology, University of Oxford, Oxford OX1 3PS, UK.}

Received: 27 July 2020 Accepted: 19 November 2020 Published online: 17 February 2021

\section{References}

1. Zaidi SA, Shahzad F, Batool S. Progress in cancer biomarkers monitoring strategies using graphene modified support materials. Talanta. 2020:210:120669.

2. Bermúdez-Humarán LG, Kharrat P, Chatel J-M, Langella P. Lactococci and lactobacilli as mucosal delivery vectors for therapeutic proteins and DNA vaccines. Microb Cell Fact. 2011;10(1):S4

3. Teusink B, Bachmann H, Molenaar D. Systems biology of lactic acid bacteria: a critical review. Microb Cell Fact. 2011;10(1):S11.

4. Ruhen O, Meehan K. Tumor-derived extracellular vesicles as a novel source of protein biomarkers for cancer diagnosis and monitoring. Proteomics. 2019;19(1-2):1800155.

5. Johnsen KB, Gudbergsson JM, Andresen TL, Simonsen JB. What is the blood concentration of extracellular vesicles? Implications for the use of extracellular vesicles as blood-borne biomarkers of cancer. Biochim Biophys Acta (BBA) Rev Cancer. 2019;1871(1):109-16.

6. Jalalian SH, Ramezani M, Jalalian SA, Abnous K, Taghdisi SM. Exosomes, new biomarkers in early cancer detection. Anal Biochem. 2019;571:1-13.

7. Pashayan $N$, Antoniou AC, Ivanus U, Esserman LJ, Easton DF, French D, Sroczynski G, Hall P, Cuzick J, Evans DG. Personalized early detection and prevention of breast cancer: ENVISION consensus statement. Nat Rev Clin Oncol. 2020;17(11):1-19.

8. Loktionov A. Biomarkers for detecting colorectal cancer non-invasively: DNA, RNA or proteins? World J Gastrointest Oncol. 2020;12(2):124.

9. Lima ZS, Ghadamzadeh M, Arashloo FT, Amjad G, Ebadi MR, Younesi L. Recent advances of therapeutic targets based on the molecular signature in breast cancer: genetic mutations and implications for current treatment paradigms. J Hematol Oncol. 2019;12(1):38.

10. Seijo LM, Peled N, Ajona D, Boeri M, Field JK, Sozzi G, Pio R, Zulueta JJ, Spira A, Massion PP. Biomarkers in lung cancer screening: achievements, promises, and challenges. J Thorac Oncol. 2019;14(3):343-57.

11. Dhummakupt ES, Rizzo GM, Feasel M, Mach PM, Tran BQ, Carmany DO, Demond PS, McBride EM, Maughan M, Sekowski JW. Proteomic and metabolomic profiling identify plasma biomarkers for exposure to ultralow levels of carfentanil. Toxicol Sci. 2019;167(2):524-35.

12. Cohen L, Keegan A, Melanson SE, Walt DR. Impact of clinical sample handling and processing on ultra-low level measurements of plasma cytokines. Clin Biochem. 2019;65:38-44.

13. Teng J, Huang L, Zhang L, Li J, Bai H, Li Y, Ding S, Zhang Y, Cheng W. High-sensitive immunosensing of protein biomarker based on interfacial recognition-induced homogeneous exponential transcription. Anal Chim Acta. 2019;1067:107-14

14. Macchia E, Sarcina L, Picca RA, Manoli K, Di Franco C, Scamarcio G, Torsi L. Ultra-low HIV-1 p24 detection limits with a bioelectronic sensor. Anal Bioanal Chem. 2020;412(4):811-8.

15. Burtis CA, Ashwood ER, Bruns DE. Tietz textbook of clinical chemistry and molecular diagnostics. Elsevier Health Sciences: St. Louis; 2012.

16. McPherson RA. Henry's clinical diagnosis and management by laboratory methods first South Asia edition. Chennai: Elsevier India; 2017. 
17. Choi W, Min YW, Lee KY, Jun S, Lee HG. Dielectrophoresis-based microwire biosensor for rapid detection of Escherichia coli K-12 in ground beef. LWT. 2020. https://doi.org/10.1016/j.lwt.2020.109230.

18. Wang L, Filer JE, Lorenz MM, Henry CS, Dandy DS, Geiss BJ. An ultra-sensitive capacitive microwire sensor for pathogen-specific serum antibody responses. Biosens Bioelectron. 2019;131:46-52.

19. Doughty PT, Hossain I, Gong C, Ponder KA, Pati S, Arumugam PU, Murray TA. Novel microwire-based biosensor probe for simultaneous real-time measurement of glutamate and GABA dynamics in vitro and in vivo. Sci Rep. 2020;10(1):1-19.

20. Timothy DP, Imran $H$, Chenggong G, Ponder KA, Sandipan P, Arumugam PU, Murray TA. Novel microwire-based biosensor probe for simultaneous real-time measurement of glutamate and GABA dynamics in vitro and in vivo. Sci Rep. 2020;10(1):1-19.

21. Singamaneni S, LeMieux MC, Lang HP, Gerber C, Lam Y, Zauscher S, Datskos PG, Lavrik NV, Jiang H, Naik RR. Bimaterial microcantilevers as a hybrid sensing platform. Adv Mater. 2008;20(4):653-80.

22. Nava Brezolin A, Martinazzo J, Blassioli-Moraes MC, Manzoli A, Steffens J, Steffens C. Highly sensitive sensor for trace level detection of euschistus heros pheromone. Ind Biotechnol. 2019;15(6):357-64.

23. Carrell C, Kava A, Nguyen M, Menger R, Munshi Z, Call Z, Nussbaum M, Henry C. Beyond the lateral flow assay: a review of paper-based microfluidics. Microelectron Eng. 2019;206:45-54.

24. Sohrabi H, Kholafazad Kordasht H, Pashazadeh-Panahi P, NezhadMokhtari P, Hashemzaei M, Majidi MR, Mosafer J, Oroojalian F, Mokhtarzadeh A, de la Guardia M. Recent advances of electrochemical and optical biosensors for detection of $\mathrm{C}$-reactive protein as a major inflammatory biomarker. Microchem J. 2020;158:105287.

25. Gutiérrez-Capitán M, Baldi A, Fernández-Sánchez C. Electrochemical paper-based biosensor devices for rapid detection of biomarkers. Sensors. 2020;20(4):967.

26. Lenz M. Control of tetrathiafulvalene-gold microstructure formation in microfluidic poly (dimethylsiloxane) devices and in situ detector application. Doctoral dissertation, ETH Zurich. 2017.

27. Sanginario A, Cauda V, Bonanno A, Bejtka K, Sapienza S, Demarchi D. An electronic platform for real-time detection of bovine serum albumin by means of amine-functionalized zinc oxide microwires. RSC Adv. 2016;6(2):891-7.

28. Omelyanchik A, Levada E, Ding J, Lendinez S, Pearson J, Efremova M, Bessalova V, Karpenkov D, Semenova E, Khlusov I. Design of conductive microwire systems for manipulation of biological cells. IEEE Trans Magn. 2018:54(6): $1-5$

29. Selid PD, Xu H, Collins EM, Striped Face-Collins M, Zhao JX. Sensing mercury for biomedical and environmental monitoring. Sensors. 2009;9(7):5446-59.

30. Mathew R, Sankar AR. A review on surface stress-based miniaturized piezoresistive SU-8 polymeric cantilever sensors. Nano-micro Lett. 2018;10(2):35.

31. Vashist SK, Luong JH. Microcantilever-based sensors handbook of immunoassay technologies. Elsevier: London; 2018. p. 305-32.

32. Haag AL. Potential-driven surface stress of a cantilever-based sensor. Doctoral Dissertation. Montreal, Canada: McGill University. 2016.

33. Mutunga E, Tyagi P. Patternable rough textured gold microwire for neurochemical sensing. MRS Adv. 2016;1(11):717-21.

34. Lv L, Han X, Wu X, Li C. The synthesis of high-aspect-ratio Au microwires with a biomolecule for electrochemical sensing. Chem Commun. 2020;56(5):743-6.

35. Zhao S, Liu X, Xu Z, Ren H, Deng B, Tang M, Lu L, Fu X, Peng H, Liu Z. Graphene encapsulated copper microwires as highly MRI compatible neural electrodes. Nano Lett. 2016;16(12):7731-8.

36. Marguš M, Superville P-J, Billon G. Understanding the gold microwire electrode behavior for the detection of trace metals. Book of. 2017:45:73.

37. Dang TKM. Microwire arrays for studying the influence of temperature gradients on the cellular behavior. Doctoral dissertation, Technische Universität München. 2018.

38. Zhou C, Yang M, Li S-S, Jiang T-J, Liu J-H, Huang X-J, Chen X. Electrochemically etched gold wire microelectrode for the determination of inorganic arsenic. Electrochim Acta. 2017:231:238-46.

39. Assis $P A D$, Andrade $S B D$, Oliveira $C M C D$, Araújo PMD, Grangeiro Júnior $S$, Ramos SVV. Development and validation of a microbial counting method for mebendazole oral suspension. Braz J Pharm Sci. 2011:47:555-63.
40. Fontes E, Nandenha J, De Souza R, Antonio F, Homem-de-Mello P, Neto A. Au core stabilizes $\mathrm{CO}$ adsorption onto Pd leading to $\mathrm{CO}_{2}$ production. Mater Today Adv. 2020;6:100070.

41. Kirichkov MV, Guda AA, Budnyk AP, Bugaev AL, Lastovina TA, Shapovalov W, Guda SA, Trigub AL, Rusalev YV, Chernyshev AV. X-ray and optical characterization of the intermediate products in the $\mathrm{Au}^{3+}$ reduction process by oleylamine. Radiat Phys Chem. 2018;175:108067.

42. Kim JK, Lee SA, Shin S, Lee JY, Jeong KW, Nan YH, Park YS, Shin SY, Kim Y. Structural flexibility and the positive charges are the key factors in bacterial cell selectivity and membrane penetration of peptoidsubstituted analog of Piscidin 1. Biochim Biophys Acta (BBA) Biomembr. 2010;1798(10):1913-25.

43. Alves CS, Melo MN, Franquelim HG, Ferre R, Planas M, Feliu L, Bardají E, Kowalczyk W, Andreu D, Santos NC. Escherichia coli cell surface perturbation and disruption induced by antimicrobial peptides BP100 and pepR. J Biol Chem. 2010;285(36):27536-44.

44. Nutting J, Nuttall J. The malleability of gold. Gold Bull. 1977;10(1):2-8.

45. Tremblay C, Wheeler G, Oteri A. PhotonAssay ${ }^{\mathrm{TM}}$-efficient \& bulk gold analysis in the modern world. ASEG Ext Abstr. 2019;2019(1):1-4.

46. Mirkin CA. In my element: gold. Chem Eur J. 2019;25(33):7777-8.

47. Wang Y, Su Y, Wang Z, Zhang Z, Han X, Dong M, Cui L, Chen M. Reversible conductivity recovery of highly sensitive flexible devices by water vapor. npj Flex Electron. 2018;2(1):1-10.

48. FrozandehMehr E, Tarlani A, Farhadi S. Cetyltrimethylammonium bromide (CTAB) bloated micelles and merged CTAB/bolaamphiphiles selfassembled vesicles toward the generation of highly porous alumina as efficacious inorganic adsorbents. Langmuir. 2019;35(34):11188-99.

49. Llombart P, Palafox MA, MacDowell LG, Noya EG. Structural transitions and bilayer formation of CTAB aggregates. Colloids Surf A. 2019;580:123730.

50. FrozandehMehr E, Tarlani A, Farhadi S. CTAB bloated micelles and merged CTAB/bolaamphiphiles self-assembled vesicles toward the generation of highly porous alumina as efficacious inorganic adsorbents. Langmuir. 2019. https://doi.org/10.1021/acs.langmuir.9b01934.

51. Vlachy N, Drechsler M, Touraud D, Kunz W. Anion specificity influencing morphology in catanionic surfactant mixtures with an excess of cationic surfactant. C R Chim. 2009:12(1-2):30-7.

52. Zhi $D$, Zhang $S$, Cui $S$, Zhao $Y$, Wang $Y$, Zhao D. The headgroup evolution of cationic lipids for gene delivery. Bioconjug Chem. 2013;24(4):487-519.

53. Kumar S, Patel H, Patil SR. Test of Hofmeister-like series of anionic headgroups: clouding and micellar growth. Colloid Polym Sci. 2013;291 (9):2069-77.

54. Domingos RF, Carreira S, Galceran J, Salaün P, Pinheiro JP. AGNES at vibrated gold microwire electrode for the direct quantification of free copper concentrations. Anal Chim Acta. 2016;920:29-36.

55. Wang H, Ebenezer V, Ki J-S. Photosynthetic and biochemical responses of the freshwater green algae Closterium ehrenbergii Meneghini (Conjugatophyceae) exposed to the metal coppers and its implication for toxicity testing. J Microbiol. 2018;56(6):426-34.

56. Sun $D$, Xiong Y, Sun Y, Dabo I, Schaak RE. Solution-synthesized In 4 SnSe4 semiconductor microwires with a direct band gap. Chem Mater. 2017:29(3):1095-8.

57. Han S, Zhang W, Qiu B, Dong H, Chen W, Chu M, Liu Y, Yang X, Hu F, Zhao YS. Controlled assembly of organic composite microdisk/microwire heterostructures for output coupling of dual-color lasers. Adv Opt Mater. 2018:6(5):1701077.

58. Xue F, Huang J, Li T, Wang Z, Zhou X, Wei L, Gao B, Zhai Y, Li Q, Xu Q. Lowering the synthesis temperature of $\mathrm{Y}_{3} \mathrm{Fe}_{5} \mathrm{O}_{12}$ by surfactant assisted solid state reaction. J Magn Magn Mater. 2018;446:118-24.

59. Zhou J, Ding J, Wan H, Guan G. Boosting photocatalytic degradation of antibiotic wastewater by synergy effect of heterojunction and phosphorus doping. J Colloid Interface Sci. 2020;582:961-8.

60. Fang Y, Meng L, Prominski A, Schaumann EN, Seebald M, Tian B. Recent advances in bioelectronics chemistry. Chem Soc Rev. 2020;49:7978-8035.

\section{Publisher's Note}

Springer Nature remains neutral with regard to jurisdictional claims in published maps and institutional affiliations. 